\title{
Changes in expression of WT1 during induced differentiation of the acute myeloid leukemia cell lines by treatment with 5-aza-2'-deoxycytidine and all-trans retinoic acid
}

\author{
LILI XIANG $^{1 *}$, JIAHE ZHOU ${ }^{2 *}$, WEIYING GU ${ }^{3}$, RONG WANG $^{4}$, JIANG WEI $^{5}$, \\ GUOQIANG QIU $^{6}$, JIANNONG CEN ${ }^{7}, \mathrm{XIAOBAO} \mathrm{XIE}^{3}$ and ZIXING CHEN ${ }^{7}$
}

Departments of ${ }^{1}$ Hematology and ${ }^{2}$ Urology, The Center Hospital of Xuzhou, Xuzhou; ${ }^{3}$ Department of Hematology;
${ }^{4}$ Laboratory of China and United States Cooperation; ${ }^{5}$ Comprehensive Laboratory; ${ }^{6}$ Hematology Laboratory,
The First People's Hospital of Changzhou, Third Affiliated Hospital of Suzhou University, Changzhou;
${ }^{7}$ Jiangsu Institute of Hematology, The First Affiliated Hospital of Suzhou University, Suzhou, Jiangsu, P.R. China

Received October 4, 2014; Accepted June 25, 2015

DOI: $10.3892 / \mathrm{ol} .2015 .4052$

\begin{abstract}
The aim of the present study was to investigate the effect of 5-aza-2'-deoxycytidine (decitabine; DAC) and all-trans retinoic acid (ATRA) on Wilms' tumor 1 (WT1) in acute myeloid leukemia (AML) in vitro. The methylation status of the WT1 promoter was analyzed using methylation-specific polymerase chain reaction (MSP). The expression level of WT1 was detected by reverse transcription-quantitative polymerase chain reaction. The effect of DAC and ATRA on cell differentiation was evaluated by flow cytometry. The WT1 gene was methylated in U937 cells, but unmethylated in SHI-1 and K562 cells; the U937 cells did not express the WT1 gene, but the SHI-1 and K562 cells highly expressed the WT1 gene. DAC and ATRA, alone or in combination, exhibited no effect on the expression level of WT1 in the U937 cells and on the differentiation of the K562 cells. The combined treatment of DAC and ATRA markedly decreased the WT1 expression levels of the SHI-1 and K562 cells, and induced the differentiation of the SHI-1 and U937 cells. In the SHI-1 cells, WT1 expression changed inversely to the dynamic changes of cluster of differentiation 11b-positive rates. In conclusion, the combined treatment of DAC and ATRA has clinical therapeutic potential in acute monocytic leukemia patients with high WT1 expression and a poor response to standard induction chemotherapy.
\end{abstract}

Correspondence to: Dr Lili Xiang, Department of Hematology, The Center Hospital of Xuzhou, 199 Jiefang South Road, Quanshan, Xuzhou, Jiangsu 221009, P.R. China

E-mail: lily_xianglili@126.com

*Contributed equally

Key words: acute myeloid leukemia, WT1 gene, differentiation, 5-aza-2'-deoxycytidine, all-trans retinoic acid

\section{Introduction}

The Wilms' tumor 1 (WT1) gene is located on the short arm of chromosome 11 and contains 10 exons. The gene encodes a DNA-binding transcription factor that is key to embryonic development (1), and has also been indicated to be essential in the development of the urogenital system (2) and Wilms' tumors. A number of studies have reported that WT1 is expressed at a high level in a range of solid cancer types, including malignant mesothelioma, and lung, breast and renal cell cancer $(3,4)$. WT1 can apparently behave either as a tumor suppressor or as an oncogene (5).

In the hematopoietic system, high expression levels of WT1 have been detected in acute myeloid leukemia (AML), acute lymphocytic leukemia and chronic myelocytic leukemia (6-8), suggesting an oncogenic role. In several studies, high levels of WT1 expression in leukemia cells at diagnosis have been identified as an unfavorable prognostic factor, resulting in a high frequency of relapse and blocking cell differentiation factor and minimal residual disease (MRD) monitoring in acute leukemia, particularly in AML (9-14).

5-Aza-2'-deoxycytidine (decitabine; DAC) is a cytosine nucleoside analogue that induces the hypomethylation of DNA and the differentiation of hematopoietic cells, and shows notable antineoplastic activity in patients with myelodysplastic syndromes (MDS) (15-17). DAC is incorporated into DNA during the $\mathrm{S}$ phase and inhibits DNA methyltransferase (DNMT) irreversibly, leading to the loss of methylation and the reactivation of silenced genes (18). A recent study reported that low-dose DAC has activity as an upfront therapy in older patients with AML (19). All-trans retinoic acid (ATRA), the most biologically active metabolite of vitamin A, is used as a targeted therapy for acute promyelocytic leukemia (APL) caused by gene fusion involving retinoic acid receptor- $\alpha$ (RARA). ATRA binds to RARA, which forms heterodimers with retinoid $\mathrm{X}$ receptor and binds to the RA response element, which results in the activation of target genes, such as myeloid-specific transcription factor CCAAT/enhancer-binding protein $\varepsilon$, causing growth arrest, 
and the apoptosis and differentiation of APL cells. ATRA also induces the proteolytic degradation of PML/RARA by ubiquitination and proteolysis $(20,21)$. Therefore, ATRA is highly effective in the treatment of APL and markedly improves the prognosis of these patients.

The WT1 gene is typically expressed in immature cluster of differentiation (CD)34-positive progenitor cells, while WT1 downregulation is associated with cell differentiation (22). This indicates that WT1 is important in hematopoietic development (23). Previous studies have shown that the WT1 promoter is methylated in certain leukemia cells and that WT1 gene expression in U937 cells is enhanced following treatment with DAC, together with a decrease of methylated and an increase of unmethylated levels in its promoter region (24). Another study reported that ATRA downregulates the activity of DNMT during APL blast differentiation in vitro and in vivo (25). In addition, Lubbert et al reported that the combination of DAC and ATRA treatment for patients $>60$ years old with de novo non-M3 AML ineligible for induction chemotherapy had a better antileukemic effect than conventional cytarabine-based induction chemotherapy regimens (26). As there are few reports on the effect of DAC and ATRA on WT1 gene expression in AML, the present study focused on investigating the effect of DAC and ATRA on the WT1 methylation status and expression levels, and on cell differentiation in AML cell lines.

\section{Materials and methods}

Materials. DAC and ATRA were purchased from Sigma-Aldrich (St. Louis, MO, USA). DAC was dissolved in $0.45 \% \mathrm{NaCl}$ containing $10 \mathrm{mM}$ sodium phosphate $(\mathrm{pH} 6.8)$ and stored at $-80^{\circ} \mathrm{C}$, and ATRA was dissolved in absolute ethanol, protected from light and stored at $-20^{\circ} \mathrm{C}$. Preliminary experiments confirmed that the solvents exhibited no effect on the cell lines.

Cell lines, cell culture and drug treatments. The human acute monocytic leukemia SHI-1 and U937 cell lines, and the human erythroleukemia K562 cell line were provided by the Jiangsu Institute of Hematology (The First Affiliated Hospital of Suzhou University, Suzhou, Jiangsu, China). The cells were cultured in suspension in RPMI-1640 medium (Gibco Life Technologies, Carlsbad, CA, USA) supplemented with $10 \%$ fetal bovine serum (Gibco Life Technologies) and incubated in standard tissue culture incubators at $37^{\circ} \mathrm{C}$ in a humidified atmosphere containing $5 \% \mathrm{CO}_{2}$. The cells were treated with $2 \mu \mathrm{mol} / 1 \mathrm{DAC}$ (2DAC) or $0.5 \mu \mathrm{mol} / 1$ ATRA (0.5ATRA) as single agents or in combination (2DAC + 0.5ATRA) simultaneously as a sequential exposure for 24,48 and $72 \mathrm{~h}$, using cell lines without drug treatment (with $10 \%$ fetal bovine serum only) as the controls.

RNA extraction and complementary (c)DNA conversion. Total RNA was extracted from freshly isolated culture cells, using a TRIzol one-step procedure (Invitrogen Life Technologies, Paisley, UK), following the manufacturer's instructions, and dissolved in diethylprocarbonate-treated water. Reverse transcription was performed using random hexamer primers for total RNA $(2 \mu \mathrm{g} / 40 \mu \mathrm{l})$ and 100 units of MuLV reverse transcriptase (Fermentas, Thermo Fisher Scientific Inc., Pitsburgh,
PA, USA) were added to the reaction mixture, obtaining a significant enhancement of the assay sensitivity. The cDNA was stored at $-20^{\circ} \mathrm{C}$.

Methylation-specific polymerase chain reaction (MSP). MSP was employed to determine the methylation status at the 5' CpG island in the WT1 promoter region. Bisulfite converts unmethylated cytosine residues to uracil, but methylated cytosines remain non-reactive. PCR amplifies uracil as thymine, while methylated cytosines are only amplified as cytosines. MSP distinguishes unmethylated alleles from methylated alleles in a given gene based on sequence changes following the bisulfite treatment of DNA using primers designed for either methylated or unmethylated DNA. The cells of different groups were collected for MSP at $48 \mathrm{~h}$ after drug treatment incubation. DNA from the cell lines was extracted using the ZR Genomic DNA II kit (Zymo Research Corporation, Irvine, CA, USA) as recommended by the manufacturer. Bisulphite modification of genomic DNA was performed using the EZ DNA Methylation-Gold kit (Zymo Research Corporation) according to the manufacturer's instructions. Polymerase chain reaction (PCR) amplification was performed using WT1 promoter gene fragment-specific primers for either methylated or unmethylated DNA (Sangon Biotech Co., Ltd., Shanghai, China) in a total reaction volume of $25 \mu \mathrm{l}$. The reaction system consisted of $2 \mu \mathrm{l}$ DNA, $0.5 \mu 1$ forward and reverse primers, respectively, $0.5 \mu \mathrm{l} \mathrm{dNTP}, 2.5 \mu \mathrm{l}$ Taq buffer,

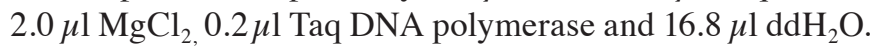
The primers were as follows: Unmethylated WT1 sense, 5'-GGT TAAGTTAGGTGTTGTTGAGGTTAGT-3' and antisense, 5'-AAACACTACTCCTCATACAACTCCACA-3', yielding a fragment of $351 \mathrm{bp}$; and methylated WT1 sense, 5'-TTGGGTTAAGTTAGGCGTCGTC-3' and antisense, 5'-AACACTACTCCTCGTACGACTCCG-3', yielding a PCR product of $353 \mathrm{bp}$. PCR was performed under the following conditions: $95^{\circ} \mathrm{C}$ for $4 \mathrm{~min}$, then $94^{\circ} \mathrm{C}$ for $25 \mathrm{sec}, 61^{\circ} \mathrm{C}$ for $25 \mathrm{sec}$ and $72^{\circ} \mathrm{C}$ for $30 \mathrm{sec}$ for 25 cycles, followed by $72^{\circ} \mathrm{C}$ for $5 \mathrm{~min}$. CpGenome universal methylated DNA (EMD Millipore, Billerica, MA, USA) was used as a control for the methylated DNA. There were five samples per experimental group, therefore, 20 samples were used per assay. PCR-amplified products were separated by electrophoresis on $2 \%$ agarose gel and visualized by ethidium bromide staining under ultraviolet light, and then images were captured.

Reverse transcription-quantitative PCR (RT-qPCR). RT-qPCR was performed with the 7500 Fast Real-Time PCR system (Applied Biosystems, Foster City, CA, USA) in a total reaction volume of $25 \mu \mathrm{l}$. The reaction system consisted of $2 \mu \mathrm{l}$ cDNA, $0.1 \mu \mathrm{l}$ forward and reverse primers, respectively, $0.1 \mu \mathrm{l}$ TaqMan probe, $0.5 \mu \mathrm{l} \mathrm{dNTP}, 2.5 \mu \mathrm{l}$ Taq buffer, $1.5 \mu \mathrm{l}$

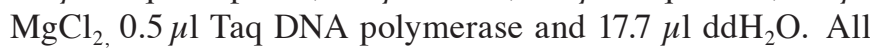
primers were synthesized by Sangon Biotech Co., Ltd. The primers and probes specific for WT1 gene were as follows: WT1 sense, 5'-AGAATACACACGCACGGTGTCT-3' and antisense, 5'-GATGCCGACCGTACAAGAGTC-3'; and WT1 TaqMan probe, 5'-CTCCAGGCACACGTCGCACATCCTC-3'. GAPDH was utilized as a housekeeping gene for internally controlling the RNA quality, for which the primers and probes were as follows: GAPDH sense, 5'-GGAAGGTGA 
AGGTCGGAGTC-3' and antisense, 5'-CGTTCTCAG CCTTGACGGT-3'; and GAPDH TaqMan probe, 5'-TTTGGT CGTATTGGGCGCCTG-3'. The reactions of the WT1 gene amplification were performed under the following conditions: $50^{\circ} \mathrm{C}$ for $2 \mathrm{~min}$ and $95^{\circ} \mathrm{C}$ for $5 \mathrm{~min}$, followed by 40 cycles of $95^{\circ} \mathrm{C}$ for $10 \mathrm{sec}, 59^{\circ} \mathrm{C}$ for $45 \mathrm{sec}$ and $37^{\circ} \mathrm{C}$ for $20 \mathrm{sec}$. The PCR profile of GAPDH was $95^{\circ} \mathrm{C}$ for $10 \mathrm{~min}$, then 40 cycles of $95^{\circ} \mathrm{C}$ for $15 \mathrm{sec}, 58^{\circ} \mathrm{C}$ for $40 \mathrm{sec}$ and $37^{\circ} \mathrm{C}$ for $1 \mathrm{~min}$. There were five samples per experimental group, therefore, 20 samples were used per assay. The resulting data were analyzed with ABI Prism 7500 SDS software (Applied Biosystems Life Technologies, Foster City, CA, USA). The cycle threshold (CT) were determined and the differences in the CT values for WT1 and GAPDH were calculated. Expression of genes with a CT $>35$ cycles was considered absent. The housekeeping GAPDH gene transcript was used to normalize the results, and the relative expression of WT1 was determined with the $2^{-\mathrm{ACT}}$ method.

Assay of cell differentiation. Expression of myelomonocytic antigens, CD11b and CD14, on the surfaces of the cell lines was determined by direct immunofluorescent staining and flow cytometry. Briefly, the cells were collected and washed with phosphate-buffered saline, and a total of $5 \times 10^{5}$ cells were stained with monoclonal mouse anti-human CD11b-pycoerythrin- (cat. no. 555388; 1:100) and monoclonal rabbit anti-human CD14- (cat. no. 555397; 1:100) fluoroscein isothiocyanate-conjugated antibodies (Sangon Biotech Co., Ltd.). The cells were incubated for $15 \mathrm{~min}$ at $4^{\circ} \mathrm{C}$ and then analyzed in a flow cytometer (FACScabilur; BD Biosciences).

Statistical analysis. All experiments were repeated three times with similar results and the data are shown as the mean \pm standard deviation. A one-way analysis of variance and coefficient correlations were performed with the statistical software SPSS 17.0 (SPSS, Inc., Chicago, IL, USA). $\mathrm{P}<0.05$ was used to indicate a statistically significant difference.

\section{Results}

Analysis of methylation status of the WT1 gene in SHI-1, U937 and K562 cells. MSP analysis was performed on cell lines treated with drugs for $48 \mathrm{~h}$. The MSP results showed that the WT1 promoter appeared to be methylation in the U937 cells. Treatment with DAC and ATRA alone or in combination did not change the methylation status of the DNA. However, the WT1 promoter was found to be unmethylated in the SHI-1 and K562 cells, and the intensity of the unmethylated band changed following DAC and ATRA treatments (Fig. 1).

Changes in mRNA expression of the WT1 gene in SHI-1, U937 and K562 cells following treatment with DAC and ATRA. The mRNA levels of the WT1 gene were detected by RT-qPCR in cell lines treated with drugs for $48 \mathrm{~h}$. The results indicated that WT1 was silenced by aberrant methylation in the U937 cells prior to treatment, and that the WT1 gene remained silenced following treatment with DAC and/or ATRA (data not shown). The expression level of WT1 was higher in the untreated SHI-1 and K562 cells. Treatment of

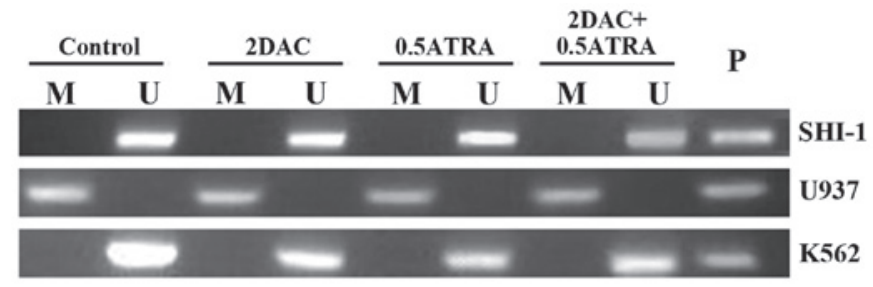

Figure 1. Methylation status of the Wilms' tumor 1 promoter in SHI-1, U937 and K562 cell lines treated with DAC and ATRA alone or in combination for $48 \mathrm{~h}$. M, methylated; U, unmethylated; P, positive control for methylated DNA; 0.5ATRA, $0.5 \mu \mathrm{mol} / 1$ all-trans retinoic acid; 2DAC, $2 \mu \mathrm{mol} / 1$ 5-aza-2'-deoxycytidine.

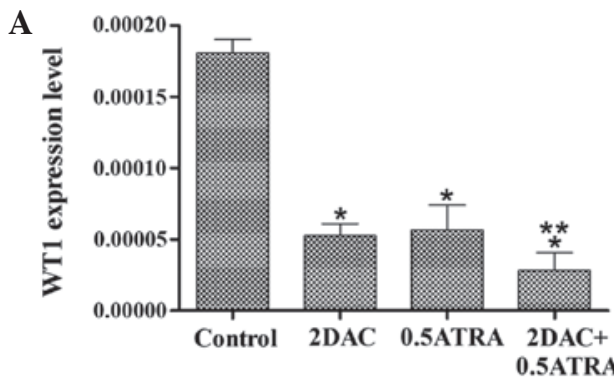

B

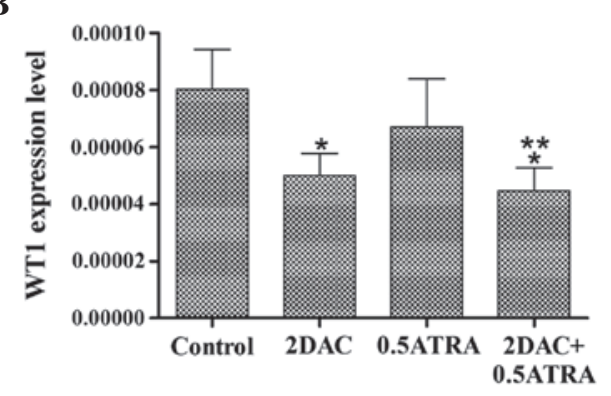

Figure 2. (A) Expression levels of WT1 mRNA in SHI-1 cells treated with DAC and ATRA alone or in combination for $48 \mathrm{~h}$. $\mathrm{P}<0.05$ vs. control group; ${ }^{* * *} \mathrm{P}<0.05$ vs. groups treated with DAC and ATRA alone. (B) Expression levels of WT1 mRNA in K562 cells treated with DAC and ATRA alone or in combination for 48 h. ${ }^{*} \mathrm{P}<0.05$ vs. control group; ${ }^{* *} \mathrm{P}<0.05$ vs. group treated with ATRA alone. 0.5ATRA, $0.5 \mu \mathrm{mol} / 1$ all-trans retinoic acid; 2DAC, $2 \mu \mathrm{mol} / 1$ 5-aza-2'-deoxycytidine; WT1, Wilms' tumor 1.

the SHI- 1 cells with DAC and ATRA alone or in combination significantly decreased the level of WT1 gene expression compared with the control group $(\mathrm{P}<0.05)$, and the combination of the two drugs resulted in a marked decrease in WT1 expression compared with DAC or ATRA alone $(\mathrm{P}<0.05)$ (Fig. 2A). The treatment of the K562 cells with DAC alone or in combination with ATRA significantly decreased the level of WT1 gene expression compared with the control group $(\mathrm{P}<0.05)$. There was a significant difference in WT1 expression between the ATRA-treated group and the combination group $(\mathrm{P}=0.031)$, but not between the $\mathrm{DAC}$-treated group and the combination group ( $\mathrm{P}=0.595$; Fig. $2 \mathrm{~B})$.

Analysis of differentiation of SHI-1, U937 and K562 cells following treatment with DAC and ATRA. The drug-treated SHI-1 and U937 cells significantly expressed CD11b compared with the control group $(\mathrm{P}<0.001)$, and the combination of DAC and ATRA treatment had a significant effect 
A

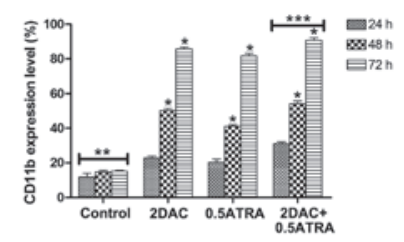

D
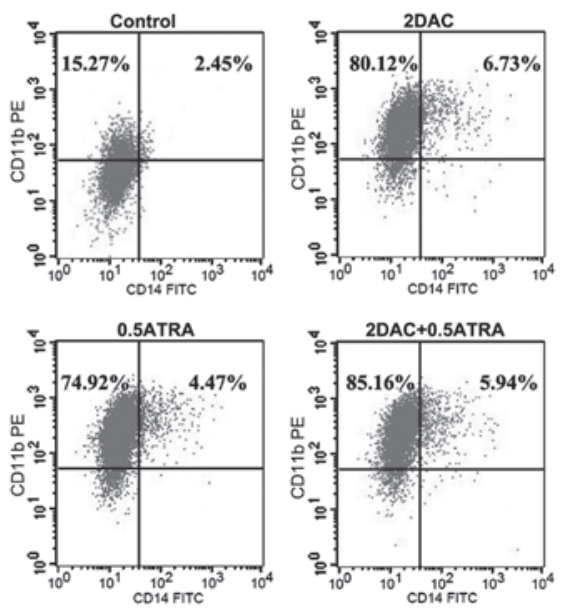

B

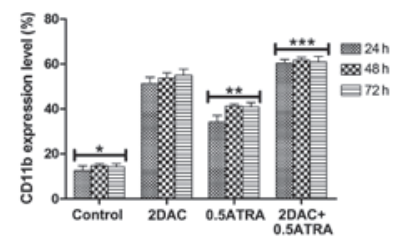

$\mathbf{E}$
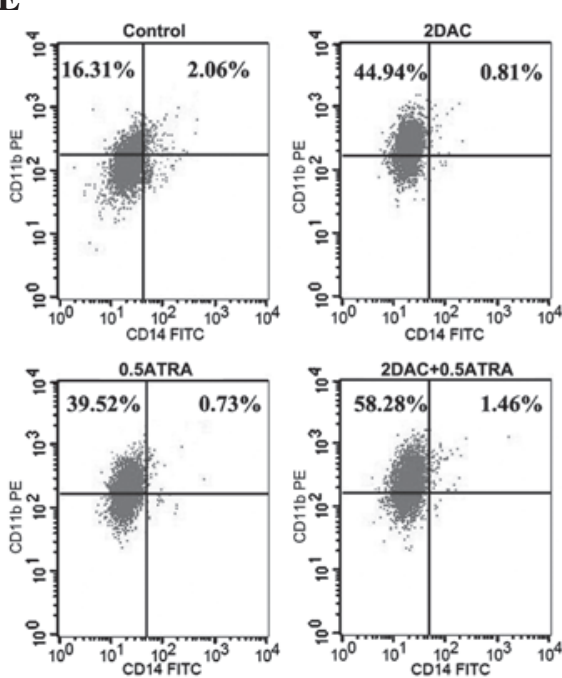

C

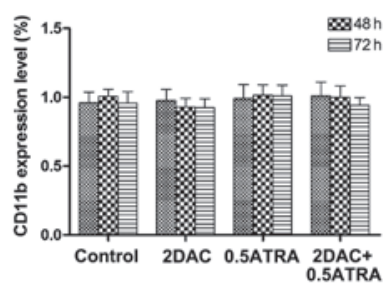

$\mathbf{F}$
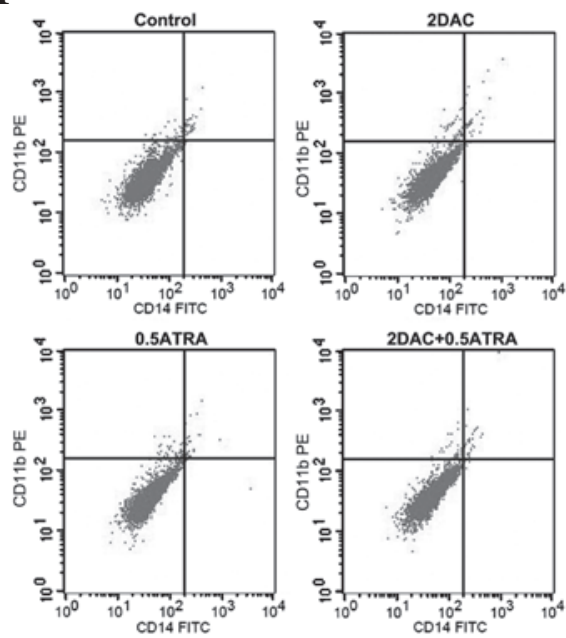

Figure 3. (A) Expression level of CD11b in SHI-1 cells treated with DAC and ATRA alone or in combination for 24,48 and 72 h. *P<0.001 vs. groups treated with DAC and ATRA alone or in combination at different time-points; ${ }^{* *} \mathrm{P}<0.001$ vs. drug-treated groups; and ${ }^{* * *} \mathrm{P}<0.05$ vs. groups treated with $\mathrm{DAC}$ and $\mathrm{ATRA}$ alone. (B) The expression level of CD11b in U937 cells treated with DAC and ATRA alone or in combination at 24,48 and $72 \mathrm{~h}$. * $<<0.001$ vs. drug-treated groups; ${ }^{* *} \mathrm{P}<0.05$ vs. groups treated with DAC alone or in combination with ATRA; and ${ }^{* * *} \mathrm{P}<0.05$ vs. groups treated with DAC and ATRA alone. (C) The expression level of CD11b in K562 cells treated with DAC and ATRA alone or in combination at 48 and $72 \mathrm{~h}$. (D) Outcome of DAC and ATRA alone or in combination on the differentiation of SHI-1 cells at $72 \mathrm{~h}$ by flow cytometry. The CD11b-positive cells were in the top left and right gates. The CD14-positive cells were in the top right and bottom right gates. (E) The outcome of DAC and ATRA alone or in combination on the differentiation of U937 cells at $72 \mathrm{~h}$ by flow cytometry. (F) The outcome of DAC and ATRA alone or in combination on the differentiation of K562 cells at $72 \mathrm{~h}$ by flow cytometry. $0.5 \mathrm{ATRA}$, $0.5 \mu \mathrm{mol} / 1$ all-trans retinoic acid; 2DAC, $2 \mu \mathrm{mol} / 1$ 5-aza-2'-deoxycytidine; CD, cluster of differentiation; FITC, fluoroscein isothiocyanate; PE, pycoerthyrin.

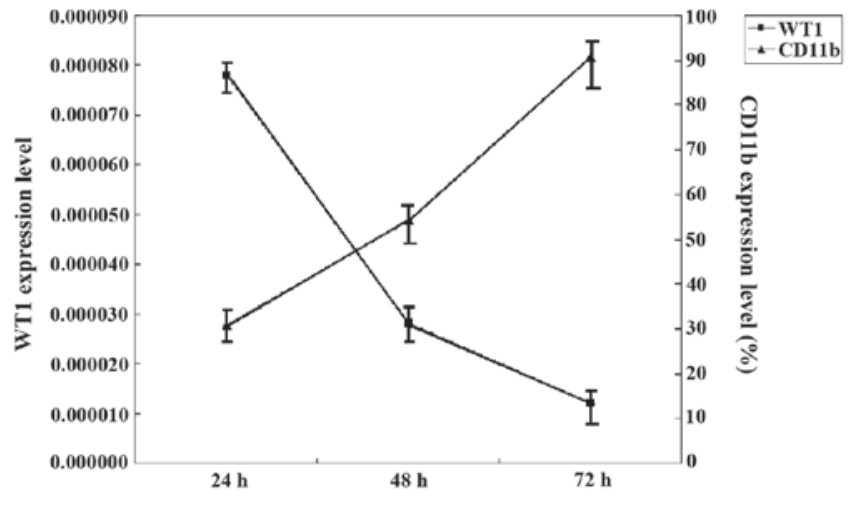

Time of SHI-1 cells treated with the combination of 2DAC and 0.5ATRA

Figure 4. A comparison of the time courses of WT1 expression and CD11b-positive rates during the combined DAC and ATRA treatment-induced differentiation of SHI-1 cells. The expression level of the WT1 gene rapidly decreased during the differentiation of SHI-1 cells induced by DAC in combination with ATRA; by contrast, the rate of CD11b expression increased gradually. 0.5ATRA, $0.5 \mu \mathrm{mol} / 1$ all-trans retinoic acid; 2DAC, $2 \mu \mathrm{mol} / 1$ 5-aza-2'-deoxycytidine; WT1, Wilms' tumor 1.

on cell differentiation compared with single-agent DAC or ATRA treatment $(\mathrm{P}<0.05)$ (Fig. $3 \mathrm{~A}$ and $\mathrm{B}$ ), whereas only marginal expression of CD14 was detected in the treated cells for any of the treatment times (data not shown). The effect of DAC and ATRA on differentiation of SHI-1 cells $(\mathrm{P}<0.05)$, but not U937 cells ( $\mathrm{P}>0.05)$, was in a time-dependent manner (Fig. 3A and B). The flow cytometry diagrams in Fig. 3C and D indicate the differentiation of SHI-1 and U937 cells, respectively. When the K562 cells were treated with the two drugs, there was no significant induction of expression of CD11b or CD14 (27).

Correlation analysis of WT1 expression levels and CDIlb-positive rates in SHI-1 cells. WT1 expression changed inversely to the dynamic changes of the CD11b-positive rates ( $r s=-0.762, \mathrm{P}=0.004$; Fig. 4). The $\mathrm{CD} 11 \mathrm{~b}$-positive rates increased as the SHI-1 cells were exposed to the combination of DAC and ATRA for increasing culture times, with a rapid decrease in the expression level of WT1.

\section{Discussion}

During embryogenesis, WT1 is preferentially expressed and is essential in the development of the urogenital system. In adults, a low level of WT1 expression is present in the kidneys, ovaries, endometrium, testes, spleen and normal hematopoietic progenitor cells $(28,29)$. Previous studies reported low levels of WT1 expression in 8226, Jurkat, Raji, U266 and U937 cells accompanying DNA hypermethylation in the WT1 gene promoter region, and 5-aza-CdR enhanced expression of the WT1 gene in U937 cells (24). The present 
study demonstrated that the U937 cells did not express the WT1 gene, but that the SHI-1 and K562 cells highly expressed the WT1 gene; the WT1 gene was methylated in the U937 cells, but unmethylated in the SHI-1 and K562 cells. Moreover, the study showed that treatment with DAC and ATRA alone or in combination did not change the methylation status of WT1 and did not induce the expression of the WT1 gene in the U937 cells.

Numerous studies have shown that WT1 is overexpressed in hematopoietic malignancies, including chronic myelogenous leukemia, acute leukemia and MDS (30-32), and in a number of leukemia cell lines (24). However, normal blood cells and CD34-positive hematopoietic progenitors have been identified to express a far lower level of WT1 or none at all $(3,30)$. The present study quantitatively analyzed the WT1 expression in AML cell lines, with results in accordance with a previous study (24). In addition, the present results showed that treatment of the SHI-1 cells with DAC and ATRA alone or in combination significantly decreased WT1 gene expression, with marked changes in WT1 expression following combined treatment DAC with ATRA, whereas treatment of the K562 cells with DAC alone or in combination with ATRA, but not with ATRA alone, significantly decreased WT1 gene expression.

Several leukemia cell lines have demonstrated a statistically significant decrease in WT1 expression level during induced differentiation $(33,34)$. The present study showed that the drug-treated SHI-1 and U937 cells markedly expressed CD11b, and the combination of DAC and ATRA treatment exhibited a pronounced effect on cell differentiation compared with DAC or ATRA treatment alone, whereas DAC and ATRA exhibited no effect on the differentiation of the K562 cells. In addition, the effect of DAC and ATRA on the differentiation of the SHI-1 cells occurred in a time-dependent manner. Due to this observation, the study then investigated the effect of DAC and ATRA on WT1 expression level and the accompanying changes in SHI-1 cell differentiation induced by the two drugs. The results showed that the expression level of the WT1 gene rapidly decreased during the differentiation of the SHI-1 cells induced by DAC in combination with ATRA; by contrast, the rate of CD11b expression increased gradually.

The majority of studies have reported that WT1 is an independent adverse prognostic factor, a convenient MRD marker, a block cell differentiation factor and a potential therapeutic target in acute leukemia $(10,14,35)$. A recent clinical study has reported that the combined treatment of DAC and ATRA exhibited a better patient response than conventional cytarabine-based induction chemotherapy (26).

Taken together, these results indicate that the combined treatment with DAC and ATRA has clinical therapeutic potential in acute monocytic leukemia patients with high WT1 expression and a poor response to standard induction chemotherapy.

\section{Acknowledgements}

The authors would like to thank the Third Affiliated Hospital of Suzhou University (Changzhou, Jiangsu, China) and the Jiangsu Institute of Hematology for providing support.

\section{References}

1. Kreidberg JA, Sariola H, Loring JM, Maeda M, Pelletier J, Housman D and Jaenisch R: WT-1 is required for early kidney development. Cell 74: 679-691, 1993.

2. Pritchard-Jones K, Fleming S, Davidson D, Bickmore W, Porteous D, Gosden C, Bard J, Buckler A, Pelletier J and Housman D: The candidate Wilms' tumour gene is involved in genitourinary development. Nature 346: 194-197, 1990.

3. Yang L, Han Y, Suarez Saiz F and Minden MD: A tumor suppressor and oncogene: The WT1 story. Leukemia 21: 868-876, 2007.

4. Nakatsuka S, Oji Y, Horiuchi T, et al: Immunohistochemical detection of WT1 protein in a variety of cancer cells. Mod Pathol 19: 804-814, 2006.

5. Morrison AA, Viney RL and Ladomery MR: The post-transcriptional roles of WT1, a multifunctional zinc-finger protein. Biochim Biophys Acta 1785: 55-62, 2008.

6. Im HJ, Kong G and Lee H: Expression of Wilms tumor gene (WT1) in children with acute leukemia. Pediatr Hematol Oncol 16: 109-118, 1999.

7. Tamaki H, Ogawa H, Ohyashiki K, Ohyashiki JH, Iwama H, Inoue K, Soma T, Oka Y, Tatekawa T, Oji Y, et al: The Wilms tumor gene WT1 is a good marker for diagnosis of disease progression of myelodysplastic syndromes. Leukemia 13: 393-399, 1999

8. Sugiyama H: Wilms tumor gene (WT1) as a new marker for the detection of minimal residual disease in leukemia. Leuk Lymphoma 30: 55-61, 1998.

9. Trka J, Kalinová M, Hrusák O, Zuna J, Krejcí O, Madzo J, Sedlácek P, Vávra V, Michalová K, Jarosová M, et al: Real-time quantitative PCR detection of WT1 gene expression in children with AML: Prognostic significance, correlation with disease status and residual disease detection by flow cytometry. Leukemia 16: 1381-1389, 2002.

10. Barragan E, Cervera J, Bolufer P, Ballester S, Martín G, Fernández P, Collado R, Sayas MJ and Sanz MA: Prognostic implications of Wilms' tumor gene (WT1) expression in patients with de novo acute myeloid leukemia. Haematologica 89: 926-933, 2004

11. Haralambieva E, Banham AH, Bastard C, Delsol G, Gaulard P, Ott G, Pileri S, Fletcher JA and Mason DY: Detection by the fluorescence in situ hybridization technique of MYC translocations in paraffin-embedded lymphoma biopsy samples. Br J Haematol 121: 49-56, 2003.

12. Ogawa H, Tamaki H, Ikegame K, Soma T, Kawakami M, Tsuboi A, Kim EH, Hosen N, Murakami M, Fujioka T, et al: The usefulness of monitoring WT1 gene transcripts for the prediction and management of relapse following allogeneic stem cell transplantation in acute type leukemia. Blood 101: 1698-1704, 2003.

13. Cilloni D, Gottardi E, De Micheli D, Serra A, Volpe G, Messa F, Rege-Cambrin G, Guerrasio A, Divona M, Lo Coco F and Saglio G: Quantitative assessment of WT1 expression by real time quantitative PCR may be a useful tool for monitoring minimal residual disease in acute leukemia patients. Leukemia 16: 2115-2121, 2002.

14. Gu W, Chen Z, Hu S, Shen H, Qiu G and Cao X: Changes in expression of WT1 isoforms during induced differentiation of the NB4 cell line. Haematologica 90: 403-405, 2005.

15. Fenaux P, Mufti GJ, Hellstrom-Lindberg E, Santini V, Finelli C, Giagounidis A, Schoch R, Gattermann N, Sanz G, List A, et al: Efficacy of azacitidine compared with that of conventional care regimens in the treatment of higher-risk myelodysplastic syndromes: A randomised, open-label, phase III study. Lancet Oncol 10: 223-232, 2009.

16. Steensma DP, Baer MR, Slack JL, Buckstein R, Godley LA, Garcia-Manero G, Albitar M, Larsen JS, Arora S, Cullen MT and Kantarjian H: Multicenter study of decitabine administered daily for 5 days every 4 weeks to adults with myelodysplastic syndromes: The alternative dosing for outpatient treatment (ADOPT) trial. J Clin Oncol 27: 3842-3848, 2009.

17. Voso MT, Santini V, Finelli C, et al: Valproic acid at therapeutic plasma levels may increase 5-azacytidine efficacy in higher risk myelodysplastic syndromes. Clin Cancer Res 15: 5002-5007, 2009.

18. Christman JK: 5-Azacytidine and 5-aza-2'-deoxycytidine as inhibitors of DNA methylation: Mechanistic studies and their implications for cancer therapy. Oncogene 21: 5483-5495, 2002. 
19. Cashen AF, Schiller GJ, O'Donnell MR and DiPersio JF: Multicenter, phase II study of decitabine for the first-line treatment of older patients with acute myeloid leukemia. J Clin Oncol 28: 556-561, 2010.

20. Donner A: Leukemia: PHFriends with RAR. Nat Chem Biol 9: 291-291, 2013

21. Yang J, Ikezoe T, Nishioka C and Yokoyama A: Over-expression of Mcl-1 impairs the ability of ATRA to induce growth arrest and differentiation in acute promyelocytic leukemia cells. Apoptosis 18: 1403-1415, 2013.

22. Gao L, Bellantuono I, Elsässer A, Marley SB, Gordon MY, Goldman JM and Stauss HJ: Selective elimination of leukemic CD34 (+) progenitor cells by cytotoxic T lymphocytes specific for WT1. Blood 95: 2198-2203, 2000.

23. Baird PN and Simmons PJ: Expression of the Wilms' tumor gene (WT1) in normal hemopoiesis. Exp Hematol 25: 312-320, 1997.

24. Zhao Y, Chen ZX, Hu SY, Cen JN and Gu WY: Study on DNA methylation status of WT1 gene in its promoter region in hematologic malignancy cell lines. Zhonghua Xue Ye Xue Za Zhi 26: 517-520, 2005 (In Chinese).

25. Fazi F, Travaglini L, Carotti D, Palitti F, Diverio D, Alcalay M, McNamara S, Miller WH Jr, Lo Coco F, Pelicci PG and Nervi C: Retinoic acid targets DNA-methyltransferases and histone deacetylases during APL blast differentiation in vitro and in vivo. Oncogene 24: 1820-1830, 2005.

26. Lubbert M, Rüter BH, Claus R, Schmoor C, Schmid M, Germing U, Kuendgen A, Rethwisch V, Ganser A, Platzbecker U, et al: A multicenter phase II trial of decitabine as first-line treatment for older patients with acute myeloid leukemia judged unfit for induction chemotherapy. Haematologica 97: 393-401, 2012

27. Xiang L, Dong W, Wang R, Wei J, Qiu G, Cen J, Chen Z, Zheng X, Hu S, Xie X, et al: All trans retinoic acid enhances the effect of 5 aza 2 ' deoxycytidine on p16INK4a demethylation, and the two drugs synergistically activate retinoic acid receptor $\beta$ gene expression in the human erythroleukemia K562 cell line. Oncol Lett 8: 117-122, 2014.
28. Sugiyama H: Wilms' tumor gene WT1: Its oncogenic function and clinical application. Int J Hematol 73: 177-187, 2001.

29. Scharnhorst V, van der Eb AJ and Jochemsen AG: WT1 proteins: Functions in growth and differentiation. Gene 273: 141-161, 2001.

30. Ariyaratana S and Loeb DM: The role of the Wilms tumour gene (WT1) in normal and malignant haematopoiesis. Expert Rev Mol Med 9: 1-17, 2007.

31. Rosenfeld C, Cheever MA and Gaiger A: WT1 in acute leukemia, chronic myelogenous leukemia and myelodysplastic syndrome: Therapeutic potential of WT1 targeted therapies. Leukemia 17: 1301-1312, 2003.

32. Gu WY, Chen ZX, Cao XS, Hu SY, Zhu J, Wang ZL, Yan F, Wang W, Cen JN, Shen HL and Qian J: Detection of WT1 expression in bone marrow of acute leukemia patients with real-time quantitative RT-PCR. Zhonghua Xue Ye Xue Za Zhi 25: 728-731, 2004 (In Chinese).

33. Sekiya M, Adachi M, Hinoda Y, Imai K and Yachi A Downregulation of Wilms' tumor gene (wt1) during myelomonocytic differentiation in HL60 cells. Blood 83: 1876-1882, 1994.

34. Wang L, Chen ZX, Fu JX, Cen JN and Wang W: Change of WT1 gene expression during induction of differentiation of NB4 cell line. Zhongguo Shi Yan Xue Ye Xue Za Zhi 9: 128-131, 2001 (In Chinese).

35. Weisser M, Kern W, Rauhut S, Schoch C, Hiddemann W, Haferlach T and Schnittger S: Prognostic impact of RT-PCR-based quantification of WT1 gene expression during MRD monitoring of acute myeloid leukemia. Leukemia 19: 1416-1423, 2005. 